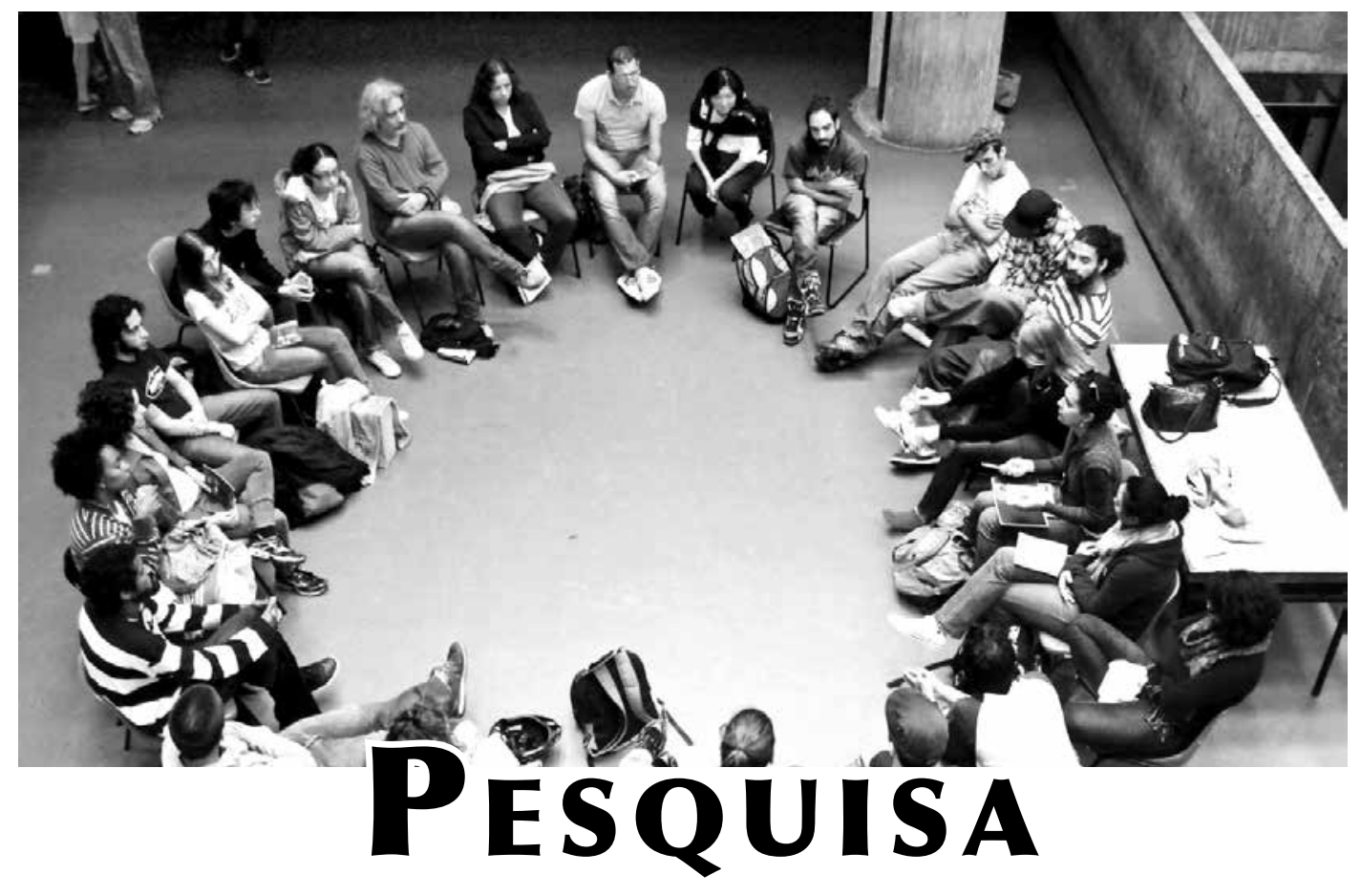




\title{
POR PEDAGOGIAS PARTICIPANTES E CRIATIVAS NA PAISAGEM E NO AMBIENTE
}

\author{
FOR PARTICIPATORY AND CREATIVE PEDAGOGY \\ IN LANDSCAPE AND ENVIRONMENT
}

\begin{abstract}
Euler Sandeville Júnior
Arquiteto e Urbanista, Arte-Educador, Pós-graduado em Ecologia, Mestre e Doutor em Estruturas Ambientais Urbanas pela FAUUSP. Professor Livre-Docente do Departamento de Projeto da FAU-USP, Vice-coordenador da Área Paisagem e Ambiente do Programa de PósGraduação em Arquitetura e Urbanismo da USP, Coordenador do Laboratório Espaço Público e Direito à Cidade, FAUUSP.

e-mail: esandeville@gmail.com. URL: http://espiral.net.br
\end{abstract}

\section{RESUMO}

Este trabalho apresenta o Núcleo de Estudos da Paisagem do Laboratório Espaço Público e Direito à Cidade, que se funda na proposição da Espiral da Sensibilidade e do Conhecimento e na conceituação da paisagem como experiências partilhadas e produção social do espaço. O trabalho argumenta sobre formas de aprender na e com a cidade, vivenciando coletiva e colaborativamente suas possibilidades, esperanças, dramas, contradições. Essa proposição estabelece um "objeto de pesquisa" relacional em muitos sentidos. Agrega a possibilidade poética a par da possibilidade de pensar a paisagem em suas estruturas territoriais, entrelaça sua dinâmica histórica com os modos de sua apropriação e transformação, exigindo a cooperação interdisciplinar, convidando à reflexão sobre a dimensão artística e sensível que mobiliza, tanto quanto da dimensão social, técnica e política. Como anexo, apresentamos a relação de pesquisas realizadas no NEP.

Palavras-chave: Paisagem, Ambiente, Processos colaborativos, Aprendizagem

\begin{abstract}
This work presents the Landscape Studies Group of the Laboratory of Public Space and Right to the City, which is based on the proposition of the Spiral of Sensibility and Knowledge and on the conception of landscape as partaken experiences as well as a social production of space. The article argues for ways of learning in and with the city, experiencing collectively and collaboratively its possibilities, hopes, dramas, contradictions. Such proposition establishes an "object of research" which is relational in many ways. It aggregates the poetical possibility along with the possibility of thinking of landscape in its territorial structures; it interlaces its historical dynamics with ways of its appropriation and transformation, requiring the interdisciplinary cooperation, inviting to the reflection of the artistic and sensible dimension that it mobilizes, as much as of its social, technical and political dimension. Attached to this text, we present the list of research carried out within the Landscape Studies Group.
\end{abstract}

Keywords: Landscape, Environment, Collaborative process, Learning

\section{A PAISAGEM ENQUANTO OBJETO DE ESTUDOS E PRÁTICAS}

"O meu conceito de arquitetura está na união e colaboração das artes, de modo que cada coisa esteja subordinada às outras e com essas em plena harmonia e, quando uso essa palavra, esse será o significado, não um mais restrito. É uma 
concepção ampla, porque abraça o inteiro ambiente da vida humana: não podemos nos subtrair da arquitetura enquanto somos parte da civilização, pois que representa o conjunto de modificações sobre a superfície terrestre, em vista das necessidades humanas. Nem podemos confiar nossos interesses a uma elite de homens preparados, pedindo a eles que investiguem, descubram e criem o ambiente destinado a nos hospedar, para depois nos admirarmos perante a obra pronta, apreendendo-a como coisa acabada. Isso cabe a nós mesmos; a cada um de nós cabe empenhar-se no controle e na proteção da orientação justa da paisagem terrestre, cada um com seu espírito e suas mãos, na parte que the cabe, para evitar que deixemos a nossos filhos um tesouro menor do que aquele que nos foi deixado por nossos pais." (WILLIAM MORRIS) ${ }^{1}$

Núcleo de Estudos da Paisagem (NEP, http://espiral.net.br) foi concebido entre 2002 e 2003 como Grupo de Pesquisa na Faculdade de Arquitetura e Urbanismo da USP2. Nosso objetivo é contribuir para a Discussão da Cultura Contemporânea na Valoração e Transformação das Paisagens por meio de formação de pesquisadores ${ }^{3}$, estudos, ações experimentais e educativas integradas. Pretendemos aprender em ação com outros parceiros. Para tanto, realizamos estudos da história da cultura e dos modos de produção e apropriação do espaço através de práticas colaborativas e participantes, e de gestão partilhada.

Os nossos fundamentos estão colocados na proposição da Espiral da Sensibilidade e do Conhecimento ${ }^{4}$ e no entendimento da paisagem como experiências partilhadas ${ }^{5}$. que significa, para nós, compreendê-las como o modo de habitar o espaço em nossa sociedade. Os desdobramentos intelectivos dessa proposição exigem reconhecê-las plenas de tensões, como espaço social, espaço vivenciado e natureza ${ }^{6}$. Nesse sentido, interessa-nos mais a contribuição que os diversos saberes disciplinares e críticos podem trazer aos estudos do ambiente e a um pensamento livre na indagação do mundo ${ }^{7}$ do que suas fronteiras, genealogias ou intransponibilidades.

A nossa aproximação da paisagem como espaço habitado, porém, não se completa na contribuição das ciências, posto que a paisagem, para ser espaço habitado, é também espaço poético e criativo. É nessa perspectiva que procuramos inseri-las em uma discussão mais ampla da cultura. Afirmá-las como experiência indica mais do que uma relação com a paisagem que seja contemplativa (teorética) ou discursivo-ideológica (que é idealização) que, por si só, podem se autonomizar como verbalismos. Propõe uma relação existencial e ativa, participante ${ }^{8}$, tanto no processo de conhecimento quanto no de sua produção social, reconhecendo-se o pesquisador um sujeito inconcluso entre outros igualmente inconclusos? ${ }^{9}$. Paisagens são então realidades processuais e relacionais, cujo destino está por ser definido.

Essa proposição convida a dar atenção às representações, aos projetos e às práticas (individuais e sociais), contraditórios e não raro tensos, em ambientes que transcendem a duração da vida humana. Abre, ainda, um enorme campo de experimentações sensíveis e cognitivas, no qual a discussão da cultura na transformação do espaço comum e do social conduzem a uma dimensão política ativa (altern-ativa) ${ }^{10}$. Pensar a paisagem 
em sua abrangência social, ambiental e existencial, significa pensar o modo como habitamos o mundo (o inteiro ambiente da vida humana de Morris), sob a ótica de sua espacialidade e temporalidade indissociáveis, que diz respeito diretamente ao avanço dos saberes no campo da arquitetura, do urbanismo ${ }^{11}$ e das questões ambientais.

ato de habitar, essencial e solidário para os viventes, é depositário de todos os nossos saberes, das contradições que engendramos em sua construção, apropriação e transformação. Para Heidegger (2008), habitar é o modo como os mortais são na terra $^{12}$. $\bigcirc$ plural - os mortais são - sugere que habitar implica conviver. No entanto, geralmente se pensa a habitação não como uma condição do ser entre e com os outros, mas como uma coisa singular ${ }^{13}$, como uma unidade individualizada e desistoricizada, esvaziada de sua produção como espaço social, existencial e cultural. Habitar, ao contrário, é fazer parte de uma história que nos antecede e nos ultrapassa, inscrita material e imaterialmente nas paisagens e nos discursos sobre suas configurações e eventos.

fruto material e imaterial do nosso fazer, do nosso trabalho, é um registro contundente de nosso aprendizado. Fala de como nos representamos. Habitar é, portanto, habitar valores, representar o mundo, escolher, aprender, ser, conhecer, partilhar, amar. Podemos reconhecê-lo como uma partilha tensa e contraditória do nosso saber/fazer em um espaço comum, ao nos apropriarmos dele de modo desigual e violento. Nosso habitar tanto tem sido indiferente ao outro, desrespeitoso, brutal, desleal, quanto tem sido afetivo, solidário, criativo, celebrativo. No fluxo cotidiano, não nos damos conta das implicações de estabelecermos entre nós uma partilha conflitiva ao realizar nossas ambições e sonhos.

Habitar é existir e, portanto, também aprender a existir, em uma paisagem em trânsito contínuo. $\bigcirc$ espaço habitado, urbano ou rural, nos abriga e, na nossa imaginação, memória, trabalho e experiência, criamos fluxos de subjetividade e de sociabilidade nesse estar contraditório ou solidário com os outros. Que tipo de educação (em sentido amplo) sustenta essas paisagens? Qual formação necessitam os sujeitos que a qualificam? $\bigcirc$ que ensinam sobre nós mesmos, e sobre nossas práticas, as paisagens e os projetos de sua transformação?

Como construir esse processo de aprendizagem? Que oportunidades temos diante de nós?

\section{UM GRUPO COLABORATIVO DE APRENDIZAGEM}

"Até o pensamento, até a invenção, são realizações coletivas, produtos do passado e do presente. Milhares de inventores prepararam a invenção de cada uma dessas máquinas, nas quais admira o homem sue gênio. Milhares de escritores, poetas e sábios têm trabalhado para elaborar o saber, extinguir o erro e criar essa atmosfera de pensamento científico, sem a qual não havia podido aparecer nenhuma das maravilhas de nosso século. Porém esses milhares de filósofos, poetas, sábios e inventores, não foram também inspirados pelo trabalho dos séculos anteriores? Não foram durante sua vida alimentados e sustentados assim no físico como no moral por 
legiões de trabalhadores e artesãos de todas as classes? Não adquiriram sua força impulsiva no que lhes rodeava?" (KROPOTKIN, 2006, p.9)

Nossos trabalhos se pautam na importância da ação individual (ela mesma devedora e suportada por inúmeros outros processos que são coletivos), mas se reconhecem, e são tecidos, em processos de cooperação. Adotamos cinco eixos, propostos na Espiral, para caracterizar nossas estratégias de conhecimento em ação e para pensar nossas próprias práticas e razões: valorização da capacidade criativa ampliando a sensibilidade ao mundo e ao outro no processo de entendimento; adoção de uma postura indagativa diante dos fenômenos; aprimoramento em processos participantes, participativos e colaborativos; compromisso social na produção de conhecimento e nas práticas, favorecendo a ação solidária a partir de um ideário pacifista e autônomo; valorização da celebração, da alegria, do prazer e da afetividade em nossas práticas ${ }^{14}$. A carta de princípios assumida pelo NEP pode ser resumida na Figura 1:

\section{espiral da sensibilidade e do conhecimento \\ este projeto deseja se opor}

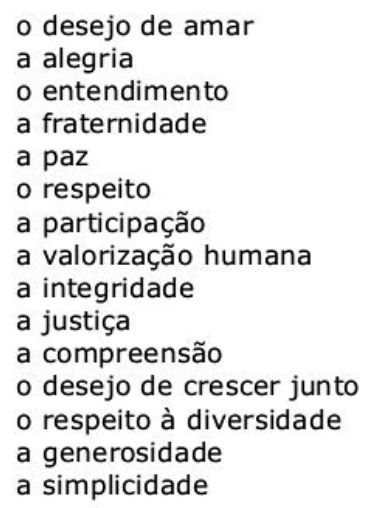

o desejo de amar
a alegria
o entendimento
a fraternidade
a paz
o respeito
a participação
a valorização humana
a integridade
a justiça
a compreensão
o desejo de crescer junto
o respeito à diversidade
a generosidade
a simplicidade

\author{
à violência \\ à padronização \\ ao preconceito \\ ao racismo \\ à guerra \\ à indignidade \\ à exploração do trabalho \\ à miséria \\ à corrupção \\ à injustiça \\ à maldade \\ à ambição \\ à exclusão \\ ao ensimesmamento \\ à camuflagem
}

Figura 1 - Princípios da Espiral da Sensibilidade e do Conhecimento partilhados para ação do NEP

Espera-se que as relações entre sensibilidade artística, experiência e a história vivida sejam fundamentais a essa proposição perante o outro e o ambiente, sobretudo a partir de projetos de educação e formação integral ${ }^{15}$. Trata-se de construir processos experimentais e afetivos de aprendizagem, sociabilidade e decisão, em ação. Espera-se reunir um conteúdo que estimule a refletir sobre o ensino e a prática social, ao indagar posturas no conhecimento das paisagens e do ambiente. Não se pode desprezar as tensões que surgem entre as diversas experiências com a paisagem e a discussão de uma nova inserção da universidade, quer no ensino, quer na produção de conhecimento, com implicações de caráter ético e político no saber e na ação, na aprendizagem ${ }^{16}$ (Figura 2).

A cidade, com suas desigualdades, demanda formas de conhecer-atuar, que exigem o confronto de contribuições teóricas com procedimentos experienciais. $\bigcirc$ campo em que se dá a experiência é espaço socialmente produzido, mas as relações que se es- 


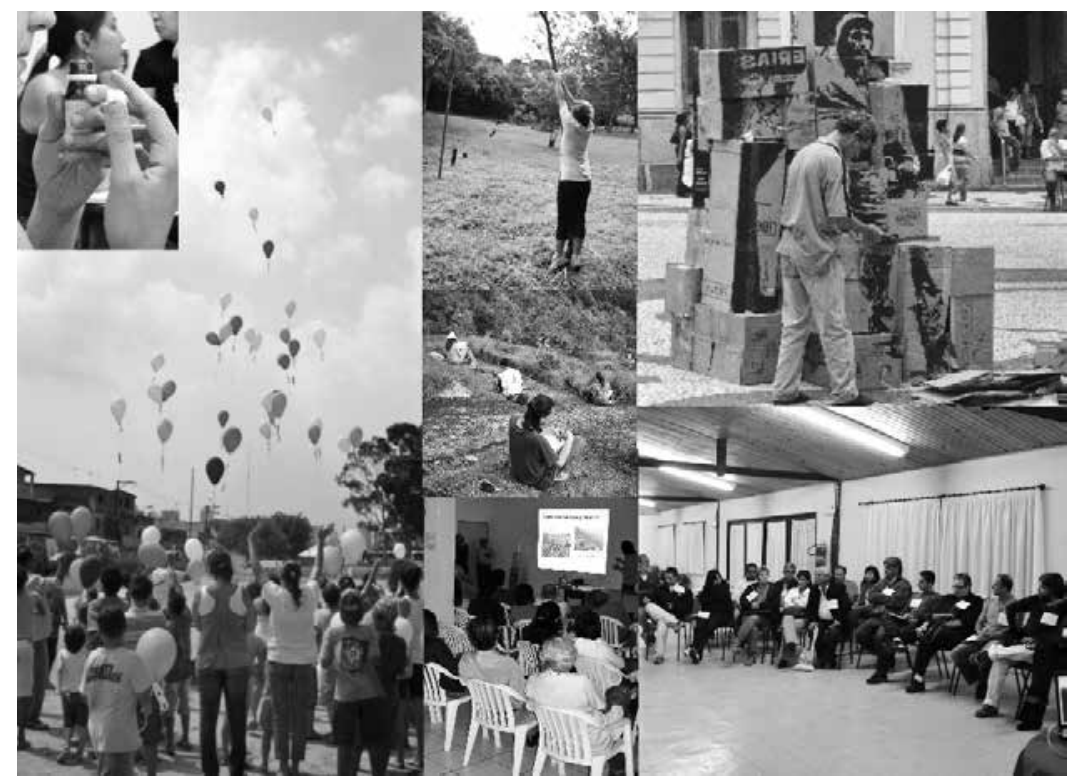

Figura 2 - Oficinas realizadas pelo NEP em diversos projetos. Acervo: NEP.

tabelecem exigem sujeitos reais, conhecer e ser conhecido pelo nome, pelas práticas, pelas representações, pelas ideologias. Compreender a paisagem como história e como lugar de experiências, significações, intersubjetividades e contradições, a torna o locus privilegiado no processo de aprendizagem, reflexão, ação criativa e da educação como construção da liberdade, do afeto e da alegria. Sabemos em ação e agimos no que sabemos, em aprendizado contínuo. As contradições dos nossos saberes são aquelas engendradas em nosso fazer e vice-versa. Fazer é acessar seletivamente nosso acervo de saberes e transformá-los em ato, dar-lhes novas configurações, torná-los um novo conhecimento, e é nesse sentido que se faz aprendizado.

Numa primeira fase (2004-2008) dos trabalhos de pesquisa do NEP procuramos desenvolver estudos exploratórios e métodos qualitativos de campo e de interpretação convergentes com a proposição de paisagem adotada. As temáticas deveriam permitir a investigação empírica promovendo o avanço metodológico. Desde o início estabelecemos estratégias de interface e vários procedimentos coletivos de cooperação entre as pesquisas ${ }^{17}$, ampliados na fase atual. Utilizamos métodos de estudo qualitativos e participantes, sobretudo a observação direta, imersão no campo ${ }^{18}$, narrativas de vida e oficinas temáticas, construídos os procedimentos no diálogo participante, buscando o entendimento dos modos locais de construir e significar paisagens em sua dimensão de realização humana e social.

Focamos prioritariamente grupos submetidos a processos de exclusão ou preconceito (comunidades rurais de agricultores e quilombolas, assentamentos urbanos periféricos, grupos com necessidades especiais) ${ }^{19}$, em áreas de interesse socioambiental, com forte sentido de lugar na maior parte das pesquisas. Foram realizados, também, alguns trabalhos que visavam estudar as dinâmicas sistêmicas da paisagem ${ }^{20}$. No âmbito das 
ações diretas voltadas para a solução de problemas, construídas dialogicamente com os nossos interlocutores, nessa primeira fase os projetos ocorreram dissociados da orientação das pesquisas ${ }^{21}$.

A partir de 2009 procuramos produzir um conhecimento que permitisse apontar também as pesquisas para ações mais concretas em colaboração com comunidades, instituições ou grupos específicos, e obter recursos para solidificação da equipe. A fim de permitir a comparação entre as pesquisas e suas questões metodológicas, bem como uma articulação não apenas conceitual, mas também operacional, adotamos como foco dos estudos do NEP a Região Metropolitana de São Paulo22. A estratégia nos permitiu a gradual integração das pesquisas com as experiências didáticas e ações desenvolvidas pelo Núcleo junto a comunidades, associações e outros contextos como fóruns, oficinas e atividades culturais e artísticas. Isso possibilitou uma maior participação dos pesquisadores no processo de construção do NEP23.

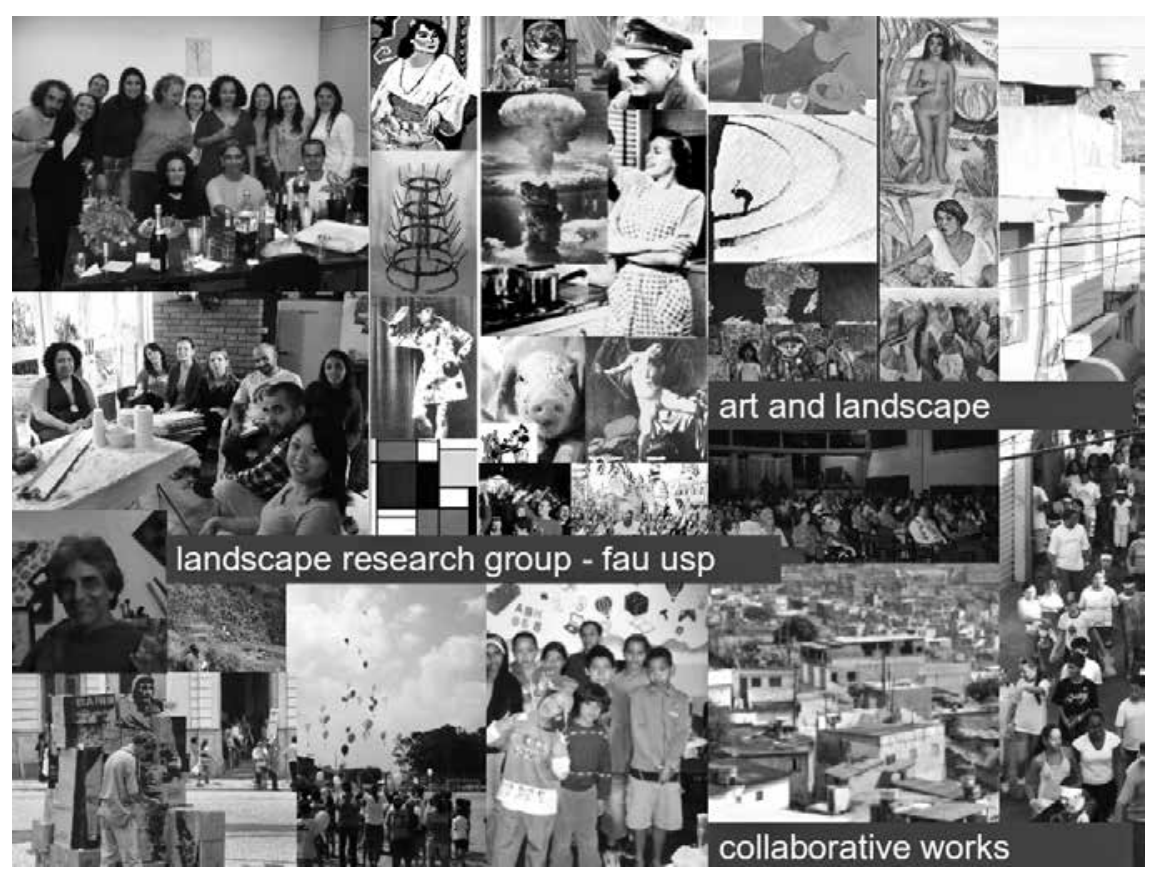

Figura 3 - Painel ilustrativo de atividades do NEP, elaborado para intercâmbio com o L'Escaut (http://www.escaut. org/), escritório de arquitetura que trabalha com processos coletivos em Bruxelas. Acervo: NEP, 2011.

A integração das pesquisas permite uma compreensão mais complexa dos processos implicados na produção e apropriação do espaço urbano. Trata-se de intencionalidade. Vai além da necessária organicidade das ações do Núcleo. Não é mera aproximação de temáticas, mas, principalmente, uma maior e mais madura integração de pesquisadores no processo de constituição do grupo, de discussão das questões de pesquisa e práticas e, sobretudo, de estabelecê-los, no conjunto mais inclusivo possível de colaboradores, como um espaço crítico de afinidade e diversidade. Contribui para a formação integral e cooperativa de seus pesquisadores, que é uma de nossas pautas. 
Retribui para a Universidade, aplicando em disciplinas de modo direto os conhecimentos que vêm sendo desenvolvidos nas pesquisas e ações do Núcleo (como relatado em Sandeville Jr., 2010a, 2010c), cria uma relação do ensino na Universidade com parceiros externos, que se aproximam nesse momento dessas atividades, contribuindo também para a sua formação. Nesse sentido, nossos trabalhos podem ser reunidos em duas linhas de pesquisa e ação, que se interpenetram, tendo como referência principal a compreensão dos processos locais e estruturais da produção do espaço na metrópole paulistana, bem como uma capacidade de cooperação com grupos empenhados em sua transformação.

\section{ESTUDOS DE TRANSFORMAÇÃO E VALORAÇÃO DAS PAISAGENS}

Essa linha tem como foco a Região Metropolitana de São Paulo. Seu eixo principal são estudos com grupos locais, visando entender suas representações e valores próprios diante da apropriação e transformação da paisagem. Essas discussões se inserem em grupos de trabalho, que devem contribuir para o entendimento das diversas escalas implicadas nesses estudos da paisagem. As pesquisas se organizam em três arcos territoriais até o momento, que permitem estabelecer processos colaborativos entre as pesquisas: Cantareira (abrangendo estudos realizados em localidades nos distritos da zona noroeste de São Paulo ${ }^{24}$, Figura 4); Mananciais (abrangendo estudos realizados na zona sul, nas bacias Billings e Guarapiranga ${ }^{25}$ ); e, Centro (ainda inicial, abrangendo estudos no arco Centro-Lapa-Butantã ${ }^{26}$ ). Os trabalhos organizam-se em dois eixos principais de pesquisa, visando adicionalmente seu rebatimento em processos educativos e participativos:

- o da construção individual e coletiva do vivido e de seus significados (no que estudos da memória e das narrativas de vida revelam-se construção do lugar);

- o da formação de capacidade interpretativa dos processos urbanos e ambientais nas escalas implicadas em que interagem suas estruturas e suas estratégias de gestão.

\section{ESTUDOS DAS ARTES, CULTURA E NATUREZA}

Essa linha dá continuidade a estudos anteriores mais gerais sobre cultura ${ }^{27}$, que visaram fundamentar discussões sobre apropriações simbólicas da natureza e da cidade. A partir de 2010, articula-se crescentemente com os trabalhos de pesquisa do NEP28. Esta linha visa a cooperação com movimentos culturais urbanos, principalmente periféricos, de resistência ou "de borda" (no que a arte ${ }^{29}$, a cultura e a educação livres, como as entendemos, têm um papel central como uma capacidade de ação urbana). Estuda movimentos contraculturais, manifestações artísticas, culturais e formas de ativismo contemporâneas que colocam em causa o espaço urbano e o espaço público, direcionando-se para a aproximação com movimentos de cultura de periferia na cidade. No entanto, são realizados também estudos que visam contribuir para a compreensão 


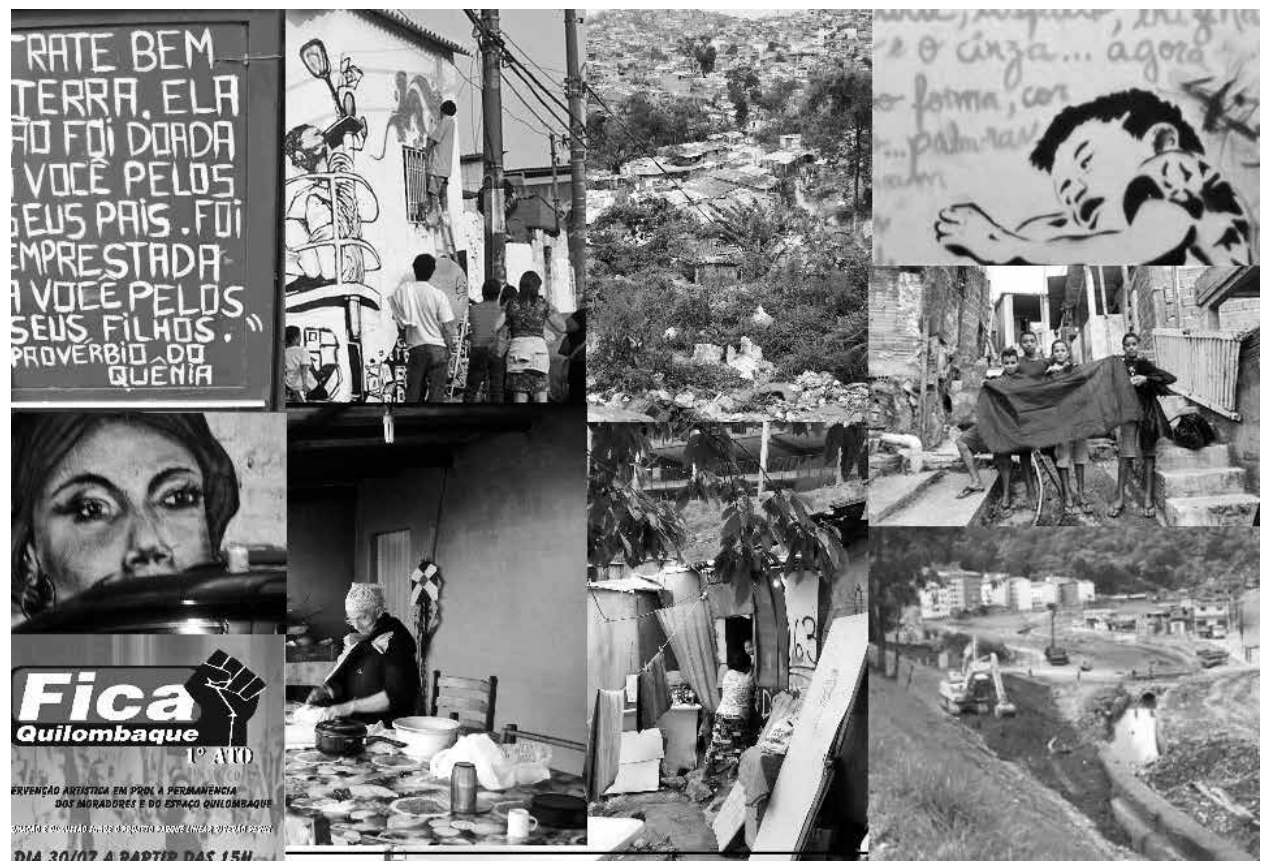

Figura 4 - Painel com frentes de atuação na zona norte: Brasilândia, Perus, Jardim Julieta, e coletivos Esquina da Memória, Comunidade Cultural Quilombaque, Centro Independente de Cultura Alternativa e Social. Fonte: http://espiral.net.br/cantareira/norte.html. Acesso em 10/17/2011.

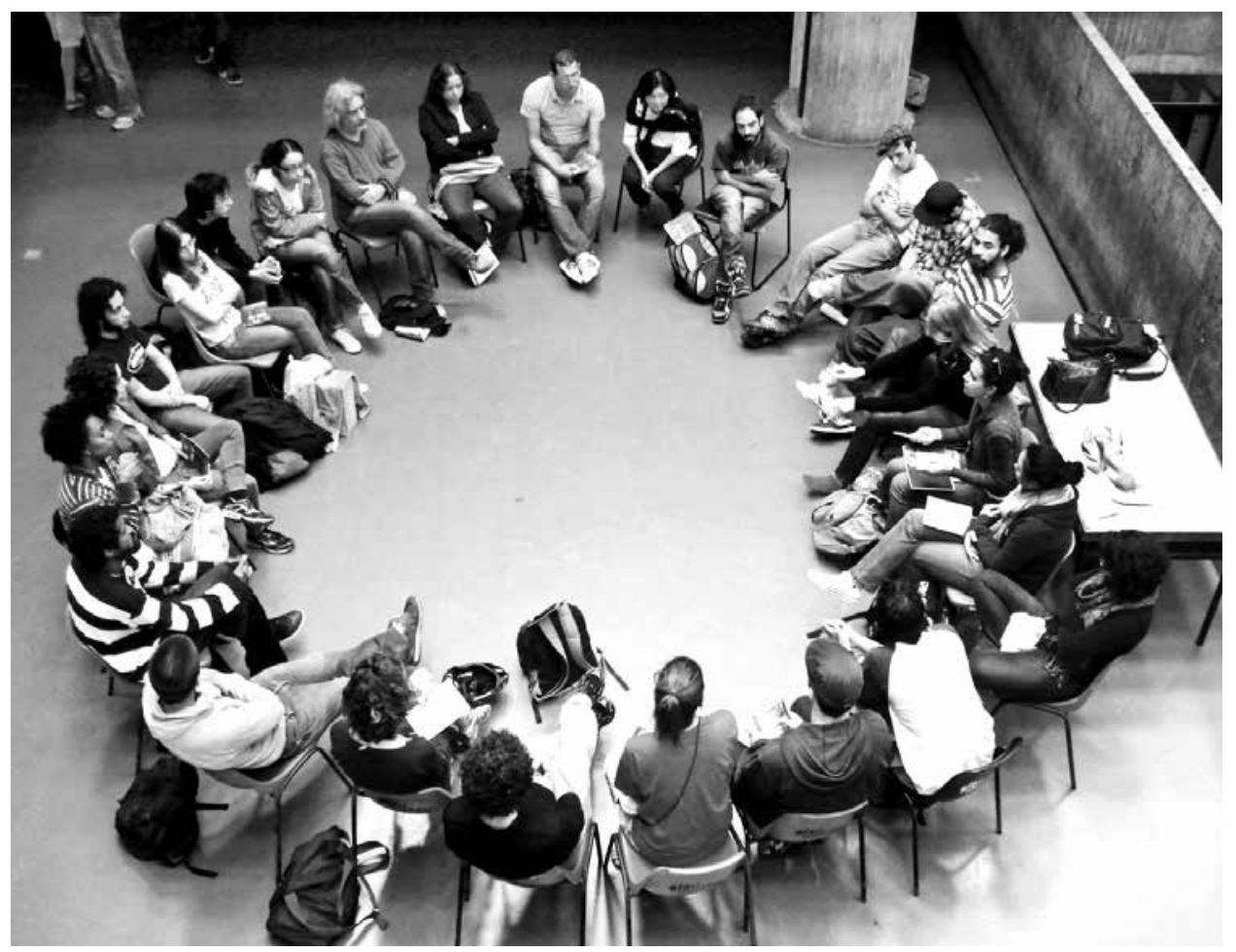

Figura 5 - Cidade e Periferia Viva. Conversa em Roda entre coletivos de arte periféricos e alunos da FAU. Compareceram: Núcleo Tembua, Projeto Cicas, Imargem, Sinfonia de Cães, Projeto Espremedor, Comunidade Cultural Sambaqui, Mutirão Cultural na Quebrada, Comboio.

Foto: Acervo NEP, 18/1 1/2011. 
histórica em uma longa duração, e estudos temáticos de natureza mais teórica ${ }^{30}$.

Na reunião de planejamento do NEP, em agosto de 2011, reafirmamos a caracterização do Núcleo como um centro de pesquisa e formação, que é entendida como a contribuição social primeira da Universidade. Organizamos subgrupos de trabalho e de estudos sobre essas linhas conforme vinculação das pesquisas. Discutimos os princípios fundadores do NEP, iniciando a reflexão sobre algumas palavras recorrentes e, portanto, estruturantes do nosso discurso. Esses termos expressam conceitos comuns aos pesquisadores e estão demandando uma maior discussão no conjunto de práticas que estamos envolvidos. Isso nos permitiu reafirmar os princípios da Espiral como fraternidade, pacifismo, não violência, não alinhamento partidário, construção de um pensamento autônomo e formas de fazer política fundadas na afetividade, na amizade, na celebração, na confiança. A discussão dos nossos processos de trabalho coloca também em questão a ampliação da elaboração de produtos acadêmicos do grupo ${ }^{31}$, tanto nos termos demandados pela academia como no retorno aos parceiros locais.

Adotamos, com base na experiência acumulada no NEP, três focos para interpretação do material de campo (sempre uma das grandes dificuldades das pesquisas qualitativas): FORMAS DE ORGANIZAÇÃO (inclusive as formas de expressão que engendram); REPRESENTAÇÕES (em discursos, narrativas, posicionamento no espaço, documentos diversos); APROPRIAÇÃO DOS ESPAÇOS (entendida em sua dimensão pública e nas diferentes localizações e conexões). Esses três nexos, ou campos interpretativos, são entendidos como formas de aprendizagem e abrigam possibilidades poéticas e contradições. São propostas como uma possibilidade de avanço sobre as conceituações inicialmente assumidas sobre paisagem e aprendizagem em ação e serão objeto de reflexão e fundamentação em outro artigo.

Abaixo, indicamos as pesquisas desenvolvidas no Núcleo de Estudos da Paisagem, a formação dos pesquisadores, sua temática de pesquisa, bolsas obtidas, ano de início e conclusão quando é o caso $^{32}$.

"Nossa primeira ideia: é preciso mudar o mundo." (DEBORD, 1957)33

\begin{tabular}{|c|c|c|c|}
\hline \multicolumn{4}{|c|}{ QUADRO 2: PESQUISAS DO NÚCLEO DE ESTUDOS DA PAISAGEM } \\
\hline Início & Conclusão & Pesquisador & Pesquisa \\
\hline & & PÓS-DOUTORADO & \\
\hline \multirow[t]{2}{*}{2011} & & $\begin{array}{l}\text { Solange Aragão (Arquiteta, } \\
\text { Pós-Doutorado em História } \\
\text { Social) }\end{array}$ & $\begin{array}{l}\text { Arte e Cidade. Representações no período } \\
\text { colonial e no Império. }\end{array}$ \\
\hline & & DOUTORADO & \\
\hline 2008 & 2012 & $\begin{array}{l}\text { Cecilia Maria de Morais } \\
\text { Machado Angileli (Arquiteta) }\end{array}$ & $\begin{array}{l}\text { Chão. } \\
\text { Bolsa FAPESP }\end{array}$ \\
\hline \multirow[t]{2}{*}{2007} & 2012 & $\begin{array}{l}\text { Silvia M. R. Valentini (Artista } \\
\text { Plástica) }\end{array}$ & $\begin{array}{l}\text { Os Sentidos da Paisagem nas pessoas que } \\
\text { não enxergam. }\end{array}$ \\
\hline & & MESTRADO & \\
\hline
\end{tabular}




\begin{tabular}{|c|c|c|c|}
\hline \multicolumn{4}{|c|}{ QUADRO 2: PESQUISAS DO NÚCLEO DE ESTUDOS DA PAISAGEM } \\
\hline Início & Conclusão & Pesquisador & Pesquisa \\
\hline 2004 & 2007 & $\begin{array}{l}\text { Cecília Maria de Morais } \\
\text { Machado Angileli (Arquiteta) }\end{array}$ & $\begin{array}{l}\text { Paisagens Reveladas no Cotidiano da } \\
\text { periferia. Distrito de Brasilândia, zona norte } \\
\text { do Município de São Paulo }\end{array}$ \\
\hline 2004 & 2007 & $\begin{array}{l}\begin{array}{l}\text { Flávia Tiemi Suguimoto } \\
\text { (Turismóloga) }\end{array} \\
\end{array}$ & $\begin{array}{l}\text { Paisagens do Médio Tietê: Formas de Uso e } \\
\text { Apropriação de suas Áquas para o Lazer }\end{array}$ \\
\hline 2005 & 2008 & $\begin{array}{l}\text { Catarina Faria Alves Silveira } \\
\text { (Bióloga) }\end{array}$ & $\begin{array}{l}\text { Lá e aqui: Estudo das práticas de } \\
\text { transformação da paisagem em } \\
\text { comunidades rurais da Zona da Mata } \\
\text { Mineira }\end{array}$ \\
\hline 2005 & 2008 & Rosana Silva Vieira (Arquiteta) & Paisagens Invisíveis: os Sertões de Ubatuba \\
\hline 2006 & 2009 & $\begin{array}{l}\text { Juliana Cavalheiro Moreno } \\
\text { (Arquiteta) }\end{array}$ & $\begin{array}{l}\text { Temporalidades da Paisagem: Uma análise } \\
\text { das temporalidades que emergem no } \\
\text { espaço de vida da comunidade quilombola } \\
\text { Pedro Cubas, Vale do Ribeira, SP }\end{array}$ \\
\hline 2004 & 2007 & $\begin{array}{l}\text { Ana Paula Veras de Paiva } \\
\text { (Arquiteta) }\end{array}$ & $\begin{array}{l}\text { Urbanização e Impactos na Paisagem } \\
\text { Litorânea: Um estudo de caso com a } \\
\text { população no Município de São Sebastião }\end{array}$ \\
\hline 2005 & 2007 & $\begin{array}{l}\text { Lucía Beatriz Bernardi de León } \\
\text { (Agrônoma) }\end{array}$ & $\begin{array}{l}\text { Aporte das áreas verdes à conservação da } \\
\text { natureza em Parque Natural Municipal, } \\
\text { Montevidéu, Uruguai } \\
\text { Bolsa PEC/PG }\end{array}$ \\
\hline 2007 & 2010 & $\begin{array}{l}\text { Cláudia Cruz Soares } \\
\text { (Pedagoga) }\end{array}$ & Heliópolis - Práticas educativas na Paisagem \\
\hline 2008 & 2011 & Andreia Broering (Geógrafa) & $\begin{array}{l}\text { Mecanismos de envolvimento comunitário e } \\
\text { gestão da Paisagem do entorno de reserva } \\
\text { particular de patrimônio natural - RPPN: } \\
\text { Estudo de caso Paulo Lopes, Santa Catarina } \\
\text { Bolsa CAPES }\end{array}$ \\
\hline 2008 & 2011 & $\begin{array}{l}\text { Mônica Y. Bierwagen } \\
\text { (Advogada) }\end{array}$ & $\begin{array}{l}\text { Sociedade de Consumo e Sustentabilidade } \\
\text { Bolsa CAPES }\end{array}$ \\
\hline 2010 & em curso & Simone Miketen (Socióloga) & $\begin{array}{l}\text { O processo de transição agroecológico no } \\
\text { contexto urbano: O caso da apa Bororé- } \\
\text { Colônia } \\
\text { Bolsa CAPES }\end{array}$ \\
\hline 2011 & em curso & Henrique Pozo (Biólogo) & $\begin{array}{l}\text { Reconstruindo paisagens: o caso da pesca } \\
\text { no Parque Estadual Xixová-Japuí, São } \\
\text { Vicente e Praia Grande, SP } \\
\end{array}$ \\
\hline 2011 & em curso & $\begin{array}{l}\text { Priscila Ikematsu (Engenheira } \\
\text { Ambiental) }\end{array}$ & $\begin{array}{l}\text { A gestão participativa das áreas de } \\
\text { mananciais da Região Metropolitana de } \\
\text { São Paulo: O caso Área de Proteção e } \\
\text { Recuperação da Bacia Hidrográfica do } \\
\text { Guarapiranga (APRM-G) }\end{array}$ \\
\hline 2011 & em curso & Gabriella Raddoll (Arquiteta) & $\begin{array}{l}\text { Potencialidades para criação de sistema } \\
\text { de espaço público de conservação e lazer } \\
\text { na área de interflúvio da Guarapiranga e } \\
\text { Billings }\end{array}$ \\
\hline
\end{tabular}




\begin{tabular}{|c|c|c|c|}
\hline \multicolumn{4}{|c|}{ QUADRO 2: PESQUISAS DO NÚCLEO DE ESTUDOS DA PAISAGEM } \\
\hline Início & Conclusão & Pesquisador & Pesquisa \\
\hline \multirow[t]{2}{*}{2011} & em curso & Lucia Omar (Geógrafa) & $\begin{array}{l}\text { Conservação Ambiental e Desenvolvimento } \\
\text { Urbano no contexto do Patrimônio Cultural: } \\
\text { Caso da ilha de Moçambique } \\
\text { Bolsa fundação FORD }\end{array}$ \\
\hline & & $\begin{array}{l}\text { MESTRADO EM PROCESSO } \\
\text { SELETIVO }\end{array}$ & \\
\hline \multirow[t]{2}{*}{2011} & & Melissa Matsunaga (Arquiteta) & $\begin{array}{l}\text { A Paisagem em intervenções de } \\
\text { requalificação urbana, o caso do Cantinho } \\
\text { do Céu }\end{array}$ \\
\hline & & INICIAÇÃO CIENTÍFICA & \\
\hline 2004 & 2005 & $\begin{array}{l}\text { Roberto Rüsche (graduação, } \\
\text { FAU) }\end{array}$ & $\begin{array}{l}\text { Potencialidades para a criação de } \\
\text { um Sistema de Espaços Públicos de } \\
\text { Conservação e Lazer na sub-bacia do } \\
\text { Córrego Padre Simplício, Jundiaí, SP }\end{array}$ \\
\hline 2008 & 2009 & $\begin{array}{l}\text { Gabriella Raddoll (graduação, } \\
\text { FAU) }\end{array}$ & $\begin{array}{l}\text { Sistemas de Espaços Livres e População em } \\
\text { bacia no Município do Embú } \\
\text { (menção honrosa no } 17 \text { SIICUSP) }\end{array}$ \\
\hline 2011 & em curso & $\begin{array}{l}\text { Rafael Siqueira (graduação, } \\
\text { FAU) }\end{array}$ & $\begin{array}{l}\text { Transformação da Paisagem e apropriação } \\
\text { dos espaços públicos no Jardim Julieta, Vila } \\
\text { Maria, São Paulo }\end{array}$ \\
\hline \multirow[t]{2}{*}{2011} & em curso & $\begin{array}{l}\text { Larissa Nebesnyi (graduação, } \\
\text { FAU) }\end{array}$ & $\begin{array}{l}\text { A margem do centro: Representações da } \\
\text { cidade em duas ocupações no centro de } \\
\text { São Paulo }\end{array}$ \\
\hline & & $\begin{array}{l}\text { TRABALHO DE GRADUAÇÃO } \\
\text { ASSOCIADO À PESQUISA }\end{array}$ & \\
\hline 2009 & 2010 & $\begin{array}{l}\text { Gabriella Raddoll (graduação, } \\
\text { FAU) }\end{array}$ & $\begin{array}{l}\text { Projeto participativo em bacia urbana, } \\
\text { Embu, SP }\end{array}$ \\
\hline \multirow[t]{2}{*}{2011} & em curso & $\begin{array}{l}\text { Gabriel Fernandes (graduação, } \\
\text { FAU) }\end{array}$ & Somos todos arquitetos \\
\hline & & $\begin{array}{l}\text { ALUNOS DE GRADUAÇÃO } \\
\text { EM PROJETOS } \\
\text { INTERUNIDADES }\end{array}$ & \\
\hline 2010 & 2011 & $\begin{array}{l}\text { Rafael Siqueira (graduação, } \\
\text { FAU) }\end{array}$ & Bolsa Convênio Dersa/USP \\
\hline 2008 & 2009 & $\begin{array}{l}\text { Gabriella Raddoll (graduação, } \\
\text { FAU) }\end{array}$ & Projeto de Políticas Públicas FAPESP \\
\hline 2010 & 2011 & $\begin{array}{l}\text { Larissa Nebesnyi (graduação, } \\
\text { FAU) }\end{array}$ & Bolsa Convênio Dersa/USP \\
\hline 2010 & 2010 & $\begin{array}{l}\text { Gabriella Raddoll (graduação, } \\
\text { FAU) }\end{array}$ & Bolsa Convênio Dersa/USP \\
\hline 2010 & 2010 & $\begin{array}{l}\text { José Muñoz (graduação, } \\
\text { intercambista) }\end{array}$ & Bolsa Convênio Dersa/USP \\
\hline 2010 & 2010 & $\begin{array}{l}\text { Andréa Conard (graduação, } \\
\text { FAU) }\end{array}$ & Bolsa Convênio Dersa/USP \\
\hline 2010 & 2010 & $\begin{array}{l}\text { André Manfrin (graduação, } \\
\text { ECA) }\end{array}$ & Bolsa da Pró-Reitoria de Extensão e Cultura \\
\hline 2011 & em curso & $\begin{array}{l}\text { Giovana Aiello (graduação, } \\
\text { FAU) }\end{array}$ & Bolsa Convênio Dersa/USP \\
\hline
\end{tabular}




\begin{tabular}{|c|c|c|c|}
\hline \multicolumn{4}{|c|}{ QUADRO 2: PESQUISAS DO NÚCLEO DE ESTUDOS DA PAISAGEM } \\
\hline Início & Conclusão & Pesquisador & Pesquisa \\
\hline & & $\begin{array}{l}\text { FORMAÇÃO DE } \\
\text { PESQUISADORES - } \\
\text { SEGUNDO GRAU }\end{array}$ & \\
\hline 2011 & em curso & Tainá Salvador & Bolsa Secretaria de Educação \\
\hline 2011 & em curso & Letícia Santos & Bolsa Secretaria de Educação \\
\hline \multirow[t]{2}{*}{2011} & em curso & Isabella Fontolam & Bolsa Secretaria de Educação \\
\hline & & $\begin{array}{l}\text { FORMAÇÃO DE } \\
\text { PESQUISADORES SEM } \\
\text { GRADUAÇÃO }\end{array}$ & \\
\hline \multirow[t]{2}{*}{2011} & em curso & Caio Castor (Fotógrafo) & $\begin{array}{l}\text { Formas de apropriação do espaço, relações } \\
\text { de poder e sociabilidade em ocupações na } \\
\text { área central de São Paulo }\end{array}$ \\
\hline & & $\begin{array}{l}\text { PROJETOS DE PESQUISA EM } \\
\text { ELABORAÇÃO }\end{array}$ & \\
\hline 2011 & & Gisele Porto (Psicóloga) & $\begin{array}{l}\text { Saraus da periferia, redes e cultura urbana } \\
\text { em São Paulo }\end{array}$ \\
\hline 2011 & & Claudia Soares (Pedagoga) & $\begin{array}{l}\text { Quando a casa vira parque. Os moradores } \\
\text { do São Vito (título sugerido) }\end{array}$ \\
\hline 2011 & & J.C. Silva (Assistente Social) & Memória dos negros na Brasilândia \\
\hline 2011 & & Mitiko Yamamoto (Pedagoga) & Memória dos japoneses na Brasilândia \\
\hline
\end{tabular}

\section{Notas}

1 A citação foi feita pela Profa. Miranda Martinelli Magnoli (1987) como indicativo de uma pauta de pesquisa.

2 O NEP deu origem, em 2005, ao LABESPAÇO, quando também foi registrado no Diretório de Grupos do CNPQ, denominado, a partir de 2010, LABCIDADE (Laboratório Espaço Público e Direito à Cidade, http:// labcidade.net.br), sendo um dos dois centros de pesquisa que estrutura esse Laboratório: o Núcleo de Estudos da Paisagem, sob coordenação do Prof. Euler Sandeville, e o de Direito à Cidade, sob coordenação da Profa. Raquel Rolnik.

3 O Núcleo acolhe pesquisadores dos níveis de segundo grau à pós-doutorado, com um grupo de estudos que se reúne regularmente há cerca de 8 anos, com 10 mestrados concluídos, 5 em curso, 2 doutorados e 1 pós-doutorado em curso, 2 iniciações científicas concluídas e 2 em curso, 3 pré-iniciações científicas em curso, entre outras atividades de formação de pesquisadores. Desenvolvemos trabalhos em interface com outros núcleos de pesquisa da Universidade em projetos e convênios científicos, parcerias com instituições públicas, associações e comunidades, cursos e programas de formação, atividades de interesse cultural e ações de natureza artística.

4 A Espiral da Sensibilidade e do Conhecimento (SANDEVILLE JR., 2003ª, 2008, 2011 1a, $2011^{\text {b }}$ ) é a proposição (a partir de 2002) de vivências poéticas baseadas em princípios criativos, colaborativos e solidários, que ultrapassam o âmbito acadêmico, mas nele se entrelaçam. Concebe o conhecimento como uma construção na existência com outros, tendo como lema um conhecimento livre e sensível, um mundo livre e em paz. Estabelece vários princípios que estão na fundação do NEP e são partilhados por seus integrantes.

5 Conforme desenvolvido em Sandeville Jr. (2004, 2005, 201 19a). Veja-se também Sandeville JR., 1987, 1993, 1999, 2010a, 2011b, 2004/2011 inédito; Sandeville JR. \& Hijioka, 2007.

6 Por espaço social pensamos em Santos (2002), Lefebvre (1991; 2001). Santos (2002), propõe o espaço como sistemas de ações e sistemas de objetos imbricados. Entretanto, não seguimos esse autor em sua forma de entender a paisagem porque a entendemos como espaço no sentido que atribui a essa palavra, como o é território, lugar, região. Nesses casos (paisagem, região, etc.), o que modifica não é a natureza ou amplitude do fenômeno, é a intencionalidade como o espaço é estudado. Para a abordagem como espaço vivenciado colhemos contribuições em Vogel e Santos (1985), Caldeira (1984), Rapoport (1978), Tuan (1980; 1983), Machado (1988), Menezes (2002), e Bosi (1987). No entanto, essa dimensão inclui também possibilidades poéticas, cujas referências ultrapassam os títulos acadêmicos, encontrando-se no próprio processo existencial (por exemplo, KEROUAK, 2006; GINSBERG, 2006; RILKE, 2007; DEBORD, 1997, 2003; SMITHSON, 2003; PIVA, 2009). Para a abordagem da natureza, seguimos, por exemplo, Sandeville JR., 1999; Rosset, 1989; Belluzzo, 1994; Dean, 1996; Lenoble, 1990; Hadot, 2004; Schama, 1996. Para a abordagem ambiental colhemos contribuições em 
McHarg, 2000; Bernáldez, 1981; Spirn, 1995; Hough, 2004; entre outros. Ao tratar de experiência tomamos como referência Bondía, 2002; em alguns sentidos Dewey, 2010; Popper, 2003 (mas não propomos seu empirismo). Entendemos pesquisa participante como uma das possibilidades da pesquisa qualitativa (DENZIN e LICOLN, 2006), que inclui (mas não se resume a ela) a possibilidade da pesquisa-ação (THIOLLENT, 2009).

7 Feyerabend, 1977; Morin, 2005.

8 Indicamos que as abordagens estritamente teóricas apresentam certos riscos, mas isso não quer dizer que a vivência no processo de conhecimento esteja desprovida destes e de outros riscos também, inclusive com a absorção do senso crítico por práticas, particularidades e projetos locais. $\bigcirc$ que fazemos é discutir essas tensões no processo de conhecimento e ação.

9 Freire, 2001.

10 Arendt $(2004)$ e Queiroga $(2001$; 2003) contribuem para pensar as esferas de vida pública como ação política no espaço urbano. Temos em mente, também, novas formas de fazer política como problematizado por Parra e Adams (2011).

11 Daí também se entende o papel de destaque e crítica ao urbanismo nas formulações de Henri Lefebvre e dos letristas e situacionistas.

12 "El modo como tú eres, yo soy, la manera según la cual los hombres somos en la tierra es el Buan, el habitar. Ser hombre significa: estar en la tierra como mortal, significa: habitar." (HEIDEGGER, 2008, s.p.)

13 O habitar não se define na casa, ou conjunto delas ou de outros programas construtivos, como no pensamento analítico-decompositivo de elementos autônomos. Mas não a menospreza, a casa não está condenada a ser elemento morfológico ou design (produto). É nosso olhar que a define. Pode ser vista, por exemplo, na dimensão do habitar, da cultura (como na oposição entre a casa e a rua, em MATTA, 1987), ou da cidade (como em VOGEL e SANTOS, 1985). A casa e a paisagem, como experiência, não são antônimos como cheio e vazio, são ambos paisagem, enquanto habitar o mundo. O que significa que a paisagem não pode ser definida por cheios e vazios, e não pode ser pensada opondo-se e excluindo alternativamente interior e exterior. $\bigcirc$ interior é uma existência na paisagem.

14 Sandeville JR., 2003a.

15 Daí nossa atenção às artes e à memória não como instrumento, mas como construção partilhada de sensibilidades e saberes.

16 Sandeville JR., 1987, 1989, 1990, 1999, 2002, 2003 ${ }^{b}, 2007^{a}, 2007^{b}, 2007^{c}, 2007^{d}, 2010^{a}, 2010^{b}, 2010^{c}$.

17 Sandeville JR., 2011 ; Sandeville JR., Broering \& Angileli, 2010.

18 Em alguns casos definimos protocolos de pesquisa e até procedimentos estruturados como questionários, entendendo-os construídos a partir do campo.

19 Angileli, 2007; Suguimoto, 2007; Silveira, 2008; Vieira, 2008; Moreno, 2009; Soares, 2010; Valentini, em curso; Broering, 2011 . Ainda assim, esses trabalhos relatam diferentes durações dessa relação de imersão, que implicam em diferentes procedimentos de pesquisa.

20 Rüsche, 2005; Bernardes, 2007; Radoll ,2009.

21 Destacam-se a ação em Salto da Divisa (MG, 2002, com a comunidade e com o Grupo de Defesa dos Direitos Humanos de Salto da Divisa, MG, através da aluna Poliana Adachi); a colaboração com moradores e associações no contexto da Operação Urbana Butantã-Vila Sônia (2006); a colaboração em torno da preservação do Patrimônio Natural da Pedra Grande em Atibaia (2007, com colaboração do Professor Sérgio Tadeu do Departamento de Ecologia da USP). Nesse período foram importantes também as ações e convívios independentes da Universidade, com coletivos de arte, cultura livre e ativismo, podendo-se destacar a colaboração ativa na rede Coro (2004-2010); o Festival Reverberações (2008); e o Jogo Urbano proposto pelo EIA (2008). Essas experiências geraram grupos de discussão autônoma, voltados para a questão do conhecimento livre e processos coletivos de criação, muitos sem qualquer vínculo organizativo que não fatores de afetividade, amizade e convicção, em que trocamos questões essenciais às nossas práticas.

22 No horizonte da Reserva da Biosfera do Cinturão Verde de São Paulo.

23 A primeira atividade, articulando as pesquisas e as ações do NEP, foi realizada em 2009 em uma disciplina no Heliópolis, com Cláudia Soares, em parceria com a União de Moradores do Heliópolis, que resultou, em 2009, no curso livre de História da Arte e, em 2010, na Oficina da Cidade, ambos realizados colaborativamente com lideranças do Heliópolis (SANDEVILLE JR., 2010, http://paisagemheliopolis.wordpress.com). Em 2010, na Brasilândia, realizamos com Cecilia Angileli nova integração entre as atividades didáticas e de pesquisa, elaborando, também em parceria com a pesquisadora, o projeto Vidas Imaginadas na Brasilândia (http:// cinemabrasilandia.wordpress.com). Em 2011, realizamos disciplina na região de mananciais, com Gabriella Radoll, Simone Miketen, Henrique Pozo, mais focada no aspecto de planejamento da paisagem.

24 Está em fase de conclusão do doutorado, de Cecilia Angileli, que deu continuidade ao mestrado, permitindo-nos avançar com uma base empírica mais cuidadosa nas questões de pesquisa-ação (http://arquiteturanafavela.blogspot.com), com a gradual implantação a partir de 2009 de um núcleo piloto do NEP, na Brasilândia. A partir de 2011 , iniciamos um outro núcleo de trabalho participativo com moradores de Perus e região.

25 A partir de 2008 um conjunto de trabalhos foi desenvolvido na zona sul, através inicialmente da cooperação 
no projeto Gov. Águas (Aprendizagem Social na Gestão de Recursos Hídricos, projeto de Políticas Públicas da FAPESP, 2008-2010, e o Convênio de Cooperação Técnica na elaboração do Plano de Manejo dos 9 parques nos municípios de Embu, Itapecerica, São Paulo, Santo André e São Bernardo, decorrentes da compensação ambiental do Rodoanel Trecho Sul (com o Laboratório de Biogeografia do Departamento de Geografia, 20092012). Várias pesquisas são desenvolvidas nessa região: Radoll, 2009, 2010; Soares, 2010, em curso Simone Miketen, Gabriella Radoll, Priscila Ikematsu, Henrique Pozo, este na Região Metropolitana de Santos, em fase inicial Melissa Matsunaga e Gisele Porto.

26 Temos os estudos de Larissa Nebesnyi e Caio Castor nas ocupações verticais na área central, em 2004-2007, nas subprefeituras do Butantã e Lapa, que necessitam ser retomados.

27 Sandeville JR., 1993, 1999, entre outros.

28 Isso possibilitou na cooperação institucional com alguns grupos (EIA e outros artistas independentes na disciplina Arte e Projeto da Paisagem, realizada no Heliópolis, 2009), parcerias com coletivos periféricos como o Cicas e Sinfonia de Cães (2010), a comunidade Quilombaque de Perus (2011), o Núcleo Tembuá (2011), o coletivo Comboio (2011), o coletivo Do Morro Produções (2011), a Rede Periferia Viva (2011, que integramos a fundação) e outros coletivos com interfaces mais eventuais, que integram uma ampla rede de ativismo e ação cultural na cidade. Alguns trabalhos já se desdobram desses: a iniciação científica de Siqueira, em parceria com - Cicas no Jardim Julieta, e a iniciação científica de Larissa Nebesnyi, em ocupações verticais em área central.

29 Em uma próxima etapa de trabalhos, prevemos a alternativa de produzir as ações artísticas e retomar os trabaIhos de interpretação das dinâmicas da natureza, seus significados e suas possibilidades poéticas, ampliando o alcance dessa linha de atuação.

30 Poderíamos remontar a Sandeville JR., 1993, 1999, e a uma série de artigos e disciplinas de pós-graduação. No âmbito da orientação à pesquisa destacam-se Bierwagen, 2011 , sobre o terceiro setor e a reorganização contemporânea do consumo, em curso pós-doutorado de Solange Aragão sobre as representações da cidade brasileira na arte até o século XIX, e o Trabalho de Conclusão de Curso de Gabriel Fernandes sobre os processos participativos na arquitetura nos anos 1970.

31 Temos 19 artigos produzidos conjuntamente sobre as pesquisas até o momento, indicados na bibliografia sob esta rubrica. Destes, 13 foram escritos em 2010 e 2011.

32 Informações mais detalhadas sobre essas pesquisas, atividades didáticas e de cooperação com parceiros externos à Universidade podem ser obtidas em Sandeville JR., $2011^{\mathrm{b}}$.

33 Com essa afirmação, Gui Debord abre o Relatório sobre a "Construção de Situações...". O Relatório foi apresentado na conferência de Corsio d'Arroscia, julho de 1957, na fundação da Internacional Situacionista. Pudéssemos nós fazer relatórios assim. O que nos impede? Até onde a padronização das atividades acadêmicas, enquanto prática e forma e, portanto, linguagem (que é pensamento), é uma padronização do pensamento e da capacidade indagativa e propositiva?

\section{Bibliografia}

ARENDT, Hannah. A condição humana. Trad. Roberto Raposo. Rio de Janeiro: Forense, 2004. [1958].

BELLUZZO, Ana Maria de Moraes. O Brasil dos viajantes. São Paulo: Odebrecht, 1994.

BERNÁLDEZ, Fernando González. Ecología y paisaje. Madri: Blume, 1981.

BONDÍA, Jorge Larrosa. Notas sobre a experiência e o saber de experiência. Revista Brasileira de Educação, Rio de Janeiro, n. 19, Jan/Fev/Mar/Abr, 2002.

BOSI, Ecléa. Memória e sociedade. Lembranças de velhos. São Paulo: Edusp, 1987. [1973].

CALDEIRA, Teresa P. R.. A política dos outros - O cotidiano dos moradores da periferia e o que pensam do poder e dos poderosos. São Paulo: Brasiliense, 1984.

DEAN, Warren. A ferro e fogo: A história e a devastação da mata atlântica brasileira. Trad. Cid Knipel Moreira. São Paulo: Companhia das Letras, 1996.

DEBORD, Guy. A sociedade do espetáculo. Rio de Janeiro: Contraponto, 1997.

. Relatório sobre a construção de situações e sobre as condições de organização e de ação da tendência situacionista internacional [1957]. In: BERENSTEIN JACQUES, Paola (Org.). Apologia da deriva: Escritos situacionistas sobre a cidade. Rio de Janeiro: Casa da Palavra, 2003.

DENZIN, Norman K. \& LICOLN, Yvonna S. (Orgs.). O planejamento da pesquisa qualitativa. Teorias e abordagens. Trad. Sandra Regina Neyz, Porto Alegre: Artmed, 2006. 
DEWEY, John. Experiência e educação. Trad. Renata Gaspar. Petrópolis, Rio de Janeiro: Vozes, 2010. [1938].

FEYERABEND, Paul. Contra o método. Esboço de uma teoria anárquica da teoria do conhecimento. Trad. Octanny S. da Mota e Leonidas Hegenberg. Rio de Janeiro: F. Alves, 1977. [1975].

FREIRE, Paulo. Educação e atualidade brasileira. São Paulo: Instituto Paulo Freire: Cortez, 2001. [1959].

GINSBERG, Allen. Uivo e outros poemas. Tradução: Claudio Willer. Porto Alegre: L\&PM, 2006.

HADOT, Pierre. O véu de Isis. Ensaio sobre a história da ideia de natureza. Trad. Mariana Sérvulo. São Paulo: Loyola, 2004.

HEIDEGGER, Martin. Construir, habitar, pensar. Disponível em: <http://www.heideggeriana.com.ar/textos/construir_habitar_pensar.htm> Acesso em: 2008.

HOUGH, Michael. Naturaleza y ciudad: Planificación urbana y procesos ecológicos. Barcelona: Gustavo Gili, 2004.

KEROUAK, Jack. On the road. Trad. Eduardo Bueno. Porto Alegre: L\&PM, 2006.

KROPOTKIN, Pedro. La conquista del plan. Trad. Léon-Ignacio. E-BooksBrasil, 2006.

LEFEBVRE, Henry. Marxismo. Trad. William Lagos. Porto Alegre: L\&PM, 2010. [1948].

O direito à cidade. Trad. Rubens Eduardo Frias. São Paulo: Centauro, 2001.

.The production of space. Trad. D. Nicholson-Smith. United Kingdom: Blackwell, 1991.

LENOBLE, Robert. História da ideia de natureza. Lisboa: Edições 70, 1990.

MACHADO, Lucy Marion C. P.. A Serra do Mar paulista: Um estudo de paisagem valorizada. Tese (Doutorado) Instituto de Geociências da Universidade Estadual Paulista. Rio Claro, 1988.

MAGNOLI, Miranda Martinelli. Memorial de titulação. Memorial. Faculdade de Arquitetura e Urbanismo da Universidade de São Paulo. São Paulo, 1987.

MATTA, Roberto da. A casa e a rua. Espaço, cidadania, mulher e morte no Brasil. Rio de Janeiro: Rocco, 1997.

MCHARG, lan.L.. Proyectar com la natureza. Barcelona: Editorial Gustavo Gili, 2000.

MENEZES, Ulpiano Bezerra de. A paisagem como fato cultural. In: YÁZIGI, Eduardo (Org.). Turismo e paisagem. São Paulo: Contexto, 2002.

MORIN, Edgar. Amor, poesia, sabedoria. Trad. Edgar de Assis Carvalho. 7.ed. Rio de Janeiro: Bertrand Brasil, 2005.

PARRA, Henrique \& ADAMS, Gavin. Nem eixo nem seixo (26 junho 201 1). Disponível em: < http://www.trezentos. blog. $b r / ? p=6070>$. Acesso em: outubro de 2011 .

PIVA, Roberto \& LEE, Wesley Duke Lee. Paranóia [1963]. Rio de Janeiro: Instituto Walter Moreira Salles, 2009.

POPPER, Karl R.. Conjecturas e refutações. Trad. Benedita Bettencourt. Coimbra: Almedina, 2003. [1962].

QUEIROGA, Eugenio F.. Praças e pracialidades em design: da visualidade da paisagem à visibilidade dos lugares. In: Seminário de Semiótica aplicada ao Design, 1, 2003, Rio de Janeiro. Anais... Rio de Janeiro: PUC-Rio, 2003.

A megalópole e a praça: $\bigcirc$ espaço entre a razão de dominação e a ação comunicativa. Tese (Doutorado) - Faculdade de Arquitetura e Urbanismo da Universidade de São Paulo. São Paulo, 2001.

RAPOPORT, Amos. Aspectos humanos de la forma urbana. Barcelona: Gustavo Gili, Perspectiva, 1978. (Colección Arquitectura.)

RILKE, Rainer Maria. Cartas a um jovem poeta. Tradução Pedro Süssekind. Porto Alegre: L\&PM, 2007.

ROSSET, Clément. A anti-natureza. Elementos para uma filosofia trágica. Rio de Janeiro: Espaço e Tempo, 1989.

SANTOS, Milton. A natureza do espaço. Técnica e tempo. Razão e emoção. São Paulo: Edusp, 2002.

SCHAMA, Simon. Paisagem e memória. São Paulo: Companhia das Letras, 1996.

SMITHSON, Robert. Um passeio pelos monumentos de Passaic. Espaço \& Debates, São Paulo, n. 43-44, p. 120 $128,2003$.

SPIRN, Anne W.. O jardim de granito. São Paulo: Edusp, 1995.

SPOSITO, Eliseu Savério. Geografia e filosofia: Contribuição para o ensino do pensamento geográfico. São Paulo: Ed. UNESP, 2004

THIOLLENT, Michel. Metodologia da pesquisa-ação. São Paulo: Cortez, 2009. 
TUAN, Yi Fu. Espaço e lugar. São Paulo: Difel, 1983.

Topofilia: Um estudo da percepção, atitudes e valores do meio ambiente. São Paulo: Difel, 1980.

VOGEL, Arno; SANTOS, Carlos Nelson F. dos (Coord.). Quando a rua vira casa. Apropriação de espaços de uso coletivo em um centro de bairro. 3.ed. Rio de Janeiro: IBAM, 1985. [Pesquisa: 1979].

\section{Artigos Citados em Coautoria no NEP}

ANGILELI, Cecília M. M. M. \& SANDEVILLE JR., Euler. Remoções na Serra da Cantareira. Caros Amigos, São Paulo. Disponível em: http://carosamigos.terra.com.br/index2/index.php/artigos-e-debates/1842-remocoes-na-serra-da-cantareira. Acesso em: 04/08/201 1, $2011^{\circ}$.

ANGILELI, Cecília Machado; SANDEVILLE JR, Euler. Chão: Uma experiência de estudo colaborativo de paisagens, Brasilândia, São Paulo. São Paulo, 201 1 , inédito.

ARAGÃO, Solange de \& SANDEVILLE Jr., Euler. Expressões de tropicalidade na pintura dos viajantes, na fotografia de paisagens e na literatura brasileira do século XIX - contrapondo olhares. In: ENCONTRO DE HISTÓRIA DA ARTE, 7, Campinas, 2010. Anais... Campinas: UNICAMP, 2010`, p.434-444.

ARAGÃO, Solange de \& SANDEVILLE Jr., Euler. Um passeio pelo jardim popular paulistano. In: ENCONTRO NACIONAL DE ENSINO DE PAISAGISMO EM ESCOLAS DE ARQUITETURA, 10, Porto Alegre, 2010. Anais... Porto Alegre: PUC-RS, $2010^{\mathrm{b}}$.

ARAGÃO, Solange de \& SANDEVILLE JR, Euler. O Passeio Público do Rio de Janeiro na literatura, na pintura e na fotografia do século XIX. São Paulo, 2011 , inédito.

BIERWAGEN, Mônica \& SANDEVILLE JR., Euler. Ecologização do consumo ou consumo do ecológico? Reflexões sobre o consumo consciente como estratégia de enfrentamento da crise ambiental. São Paulo, 2011 , inédito.

BROERING, Andréia \& SANDEVILLE JR., Euler. RPPN uma contribuição sociocultural na paisagem. In: SEMINÁRIO DE ÁREAS VERDES, III, São Paulo, 2010. Livro dos Trabalhos. São Paulo: Secretaria do Verde e do Meio Ambiente, 2010 , v. 1, p. 61-68.

IKEMATSU, Priscila \& SANDEVILLE JR., Euler. Obstáculos, conflitos e desafios no planejamento e gestão da Área de Proteção e Recuperação dos Mananciais da Bacia Hidrográfica do Guarapiranga (APRM-G). In: ENCONTRO INTERNACIONAL DA GOVERNANÇA DA ÁGUA: DESAFIOS INTERDISCIPLINARES, III, São Paulo, 2011 . Anais... São Paulo: PROCAM-USP, 2011.

MORENO, Juliana \& SANDEVILLE JR., Euler. Território e barragem: as lutas nas comunidades quilombolas do Vale do Ribeira. In: Seminário Internacional GovernanÇa da Água na America Latina, i, São Paulo, 2007. Anais... São Paulo: PROCAM-USP, 2007.

SANDEVILLE JR., Euler; BROERING, Andréia; MACHADO, Cecilia Maria de Moraes. Paisagem, Cultura e Participação Social. In: ENCONTRO NACIONAL DE ENSINO DE PAISAGISMO EM ESCOLAS DE ARQUITETURA, 10, Porto Alegre, 2010. Anais... Porto Alegre: PUC-RS, 2010.

SANDEVILLE JR. Euler \& RADOLL, Gabriella. Dinâmicas da paisagem: Espaço público, infraestrutura verde e participação social nas políticas públicas. Arq.Urb- Revista eletrônica de Arquitetura e Urbanismo, v. 4, p. 55-79, 2010.

SANDEVILLE JR., Euler \& ANGILELI, Cecília Maria de Morais Machado. Paisagem e Lazer: Representações da metrópole (para os brasileiros de Brasilândia). Revista OLAM, Rio Claro, 2005.

SANDEVILLE JR., Euler \& HIJOKA, Akemi. Flores da cerejeira e da paineira (paisagens). Paisagem e Ambiente, São Paulo, v. 24, p. 201-207, 2007.

SANDEVILLE JR., Euler \& SUGUIMOTO, Flávia Tiemi. A Natureza do Ecoturismo. In: SEMITUR - SEMINÁRIO DE PESQUISA EM TURISMO DO MERCOSUL, V, Caxias do Sul, 2008. Anais... Caxias do Sul: Universidade de Caxias do Sul, 2008, p. 1 - 12 .

SANDEVILLE JR., Euler \& SUGUIMOTO, Flávia Tiemi. Ecoturismo e (Des) Educação Ambiental. Revista Brasileira de Ecoturismo, v.3, p. 1, 2010.

SANDEVILLE JR., Euler; IKEMATSU, Priscila; MIKETEN, Simone; RADOLL, Gabriella. Dinâmicas urbanas e pesquisas do núcleo de estudos da paisagem na área de mananciais. 2011, inédito.

SANDEVILLE JR., Euler; SIQUEIRA, Rafael Gustavo Silva; NEBESNYJ, Larissa. Por espaços de cultura livre e ativa na cidade de São Paulo. In: A cultura em luta pela paz. São Paulo: Sinfonia de Cães, Centro Independente de Cultura Alternativa e Social, Centro Cultural da Juventude Ruth Cardoso, Secretaria de Cultura de São Paulo, 2011. 
VAZ, Daniela \& SANDEVILLE JR., Euler. Passeios no Parque - Acesso a todos. In: Seminário Nacional - Acessibilidade no Cotiano I, Rio de Janeiro, 2004. Anais... Rio de Janeiro: UFRJ - Núcleo Pro-Arq, 2004.

VIEIRA, Rosana \& SANDEVILLE JR., Euler. A construção das paisagens dos sertões litorâneos. OLAM, Rio Claro, v. 7, p. 1, 2007.

\section{Pesquisas Citadas Desenvolvidas no NEP}

ANGILELI, Cecília Machado. Paisagens reveladas no cotidiano da periferia. Distrito de Brasilândia, zona norte do município de São Paulo. Dissertação (Mestrado) - Faculdade de Arquitetura e Urbanismo da Universidade de São Paulo. São Paulo, 2007.

BERNARDI, Lucia. O aporte das áreas verdes à conservação da natureza em Parque Natural Municipal, Montevidéu, Uruguai. Dissertação (Mestrado) - Faculdade de Arquitetura e Urbanismo da Universidade de São Paulo. São Paulo, 2007.

BIERWAGEN, Mônica. Sociedade de consumo e sustentabilidade. Dissertação (Mestrado) - PROCAM. Universidade de São Paulo. São Paulo, 2011.

BROERING, Andéia. Mecanismos de envolvimento comunitário e gestão da paisagem do entorno de reserva particular de patrimônio natural - RPPN: Estudo de caso Paulo Lopes, Santa Catarina. Dissertação (Mestrado) - PROCAM. Universidade de São Paulo. São Paulo, 2011.

MORENO, Juliana Cavalheiro. Comunidades quilombolas do Vale do Ribeira. Relatório de pesquisa de aperfeiçoamento. Revista Cidade Sem Nome, São Paulo, v. 3, 2006.

MORENO, Juliana Cavalheiro. Comunidades quilombolas no entorno do parque estadual intervales: Análises das relações e transformações da paisagem. Dissertação (Mestrado) - PROCAM. Universidade de São Paulo. São Paulo, 2009.

PAIVA, Ana Paula. Urbanização e impactos na paisagem litorânea: Um estudo de caso no município de São Sebastião. Dissertação (Mestrado) - Faculdade de Arquitetura e Urbanismo da Universidade de São Paulo. São Paulo, 2007.

RADOLL, Gabriela. Sistemas de espaços livres e população em bacia no município do Embú. Iniciação Científica Faculdade de Arquitetura e Urbanismo da Universidade de São Paulo. São Paulo, 2009.

RÜSCHE, Roberto. Potencialidades para a criação de um sistema de espaços públicos de conservação e lazer na sub-bacia do Córrego Padre Simplício, Jundiaí, SP. Iniciação Científica - Faculdade de Arquitetura e Urbanismo da Universidade de São Paulo. São Paulo, 2005.

SILVEIRA, Catarina Faria Alves. Paisagem: Lá e aqui: estudo das práticas de transformação da paisagem em comunidades rurais da Zona da Mata Mineira. Dissertação (Mestrado) - PROCAM. Universidade de São Paulo. São Paulo, 2008.

SOARES, Cláudia Cruz. Heliópolis: Paisagem que educa. Dissertação (Mestrado) - Faculdade de Arquitetura e Urbanismo da Universidade de São Paulo. São Paulo, 2010.

SUGUIMOTO, Flávia Tiemi. Paisagens do médio Tietê: Formas de uso e apropriação de suas águas para lazer. Dissertação (Mestrado) - Faculdade de Arquitetura e Urbanismo da Universidade de São Paulo. São Paulo, 2007.

VIEIRA, Rosana. Paisagens invisíveis: os sertões de Ubatuba. Dissertação (Mestrado) - Faculdade de Arquitetura e Urbanismo da Universidade de São Paulo. São Paulo, 2008.

\section{Bibliografia Citada do Autor}

SANDEVILLE Jr., Euler. Des-vendar é explicar e explicitar, mas é também insinuar e instigar. Paisagem e paisagismo: questões de teoria e método. Trabalho Final de Disciplina. Faculdade de Arquitetura e Urbanismo da Universidade de São Paulo. São Paulo, 1987. (mimeo)

SANDEVILLE JR., Euler. Relatório. Proposta de desenvolvimento de Plano de Paisagem, Convênio com a Universidade e Formação de Quadros na PMSP, doc. 1, 23.08.89. São Paulo: Prefeitura do Município de São Paulo, 1989. (mimeo) 
SANDEVILLE JR., Euler. Paisagem e Meio Ambiente. Colaboração Universidade - Poder Público: frente e verso. In: Seminário Natureza e Prioridades de Pesquisa em Arquitetura, São Paulo, 1990. Anais... São Paulo: FAUUSP, 1990.

SANDEVILLE JR., Euler. A Herança da Paisagem. Dissertação (Mestrado) - Faculdade de Arquitetura e Urbanismo da Universidade de São Paulo. São Paulo, 1993.

SANDEVILLE JR., Euler. As Sombras da Floresta. Vegetação, Paisagem e Cultura no Brasil. Tese (Doutorado) - Faculdade de Arquitetura e Urbanismo da Universidade de São Paulo. São Paulo, 1999.

SANDEVILLE JR., Euler. O que sabem os que sabem? O universo simbólico das quantidades na educação. São Paulo: Ambiente Brasil, 2002.

SANDEVILLE JR., Euler. Espiral da Sensibilidade e do Conhecimento (memorial 2003). Disponível em: <http://espiral. net.br>. Acesso em: 01 de março de 2010. 2003․

SANDEVILLE JR., Euler. $O$ que fazer com a universidade e o ensino de paisagismo agora? In: ENCONTRO NACIONAL DE ENSINO DE PAISAGISMO EM ESCOLAS DE ARQUITETURA, 6, Recife, 2003. Anais... Recife: UFPE, $2003^{\text {b. }}$

SANDEVILLE JR., Euler. Paisagens e métodos. Algumas contribuições para elaboração de roteiros de estudo da paisagem intraurbana. Paisagens em Debate, São Paulo, v. 2, p. 1. 2004.

SANDEVILLE JR., Euler. Paisagem. Paisagem e Ambiente, São Paulo, v. 20, p. 47-60. 2005.

SANDEVILLE JR., Euler. Disciplina e Conhecimento. In: SEMINÁRIO ENSINO DE ARQUITETURA E URBANISMO, I, 2007, São Paulo. Anais... São Paulo: FAUUSP, 2007.

SANDEVILLE JR., Euler. Fundamentos. In: SEMINÁRIO ENSINO DE ARQUITETURA E URBANISMO, I, 2007, São Paulo. Anais... São Paulo: FAUUSP, 2007b.

SANDEVILLE JR., Euler. Participação e universidade. Universidade e participação. In: Seminário Nacional Paisagem e Participação: Práticas no Espaço Livre Público, São Paulo, 2007. Anais... São Paulo, 2007c.

SANDEVILLE JR., Euler. Fórum Permanente da Paisagem: Bacia Pirajussara. Pós. Revista do Programa de Pós-Graduação em Arquitetura e Urbanismo da FAUUSP, São Paulo, v. 21, 2007.

SANDEVILLE JR., Euler. Manifesto espiral. Revista digital Cidade sem Nome, São Paulo, n. 6. 2008. Disponível em: <http://www.cidadesemnome.org.br/indice5.html>. Acesso em: 01/05/2010, 2008.

SANDEVILLE Jr., Euler. A Paisagem do Município como Território Educativo. In: PADILHA, Paulo R.; CECCON, Sheila e RAMALHO, Priscila (Orgs.). Município que Educa: Fundamentos e propostas. São Paulo: EDL, vol. 1, nov., $2010^{a}$.

SANDEVILLE JR., Euler. Paisagens vivenciadas, educação-pesquisa-aprendizado em ação. In: ENCONTRO NACIONAL DE ENSINO DE PAISAGISMO EM ESCOLAS DE ARQUITETURA, 10, Porto Alegre, 2010. Anais... Porto Alegre: PUC-RS, $2010^{\mathrm{b}}$.

SANDEVILLE JR., Euler. Aprender sobre a cidade ou aprender com a cidade? Projeto Arte no Heliópolis (2009). Pós. Revista do Programa de Pós-Graduação em Arquitetura e Urbanismo da FAUUSP, v. 1, p. 70, $2010^{\circ}$.

SANDEVILLE Jr., Euler. Paisagens são experiências partilhadas. São Paulo, 2004-2011 inédito.

SANDEVILLE JR., Euler. As Paredes, A Paisagem, As Formas da Morte, As Possibilidades da Vida. São Paulo: Plêiade: AION, $2011^{\mathrm{a}}$.

SANDEVILLE JR., Euler. Paisagens Partilhadas. Tese (Livre-Docência) - Faculdade de Arquitetura e Urbanismo da Universidade de São Paulo. São Paulo, $2011^{\text {b }}$. 